\title{
Overall comparative analysis of management and outcomes of cardiac cases reported on board merchant ships
}

\author{
Charalampos Apostolatos, Vivian Andria, Julie Licari
}

Med Solutions International, United States

\begin{abstract}
Background: Telemedical assistance has always been the cornerstone of medical care on board. Significant technological progress has provided improved scientific tools and equipment for high-quality communication and prompt management of either minor incidents or major emergencies on board. Med Solutions International is a medical management company, offering services exclusively to the maritime industry. Registered vessels contact the medical team and healthcare professionals provide immediate guidelines for onboard management as well as necessary action thereafter, i.e. examination ashore or urgent medical evacuation. Since cardiac conditions or diseases are potentially the most dangerous when traveling at sea, it is of major importance to analyse and evaluate the overall management and outcomes of cases reporting symptoms of possible heart disease so as to improve telemedical assistance services in future. Materials and methods: The study included cases reporting cardiac symptoms from 5 major shipping companies during the year 2016. Data was collected from telecommunication, emails and seafarers' final medical reports. A descriptive analysis of overall management and outcomes was performed.

Results: The study showed that the number of confirmed cardiovascular cases on board was very low. Among 551 total cases and 44 cases with reported cardiac symptoms there was only one heart attack, one pulmonary oedema and one suspected myocarditis. In the majority of cases, chest pain was musculoskeletal or due to respiratory infection. Symptoms resulting from issues such as stress or anxiety often present as potential cardiac conditions. Stress may also amplify the severity of symptoms. Language barriers between the seafarer, the master and the doctor often make communication very difficult.

Conclusions: According to our findings there are grounds to intensify the prevention process through more efficient pre-employment medical examinations and improve management on board through more intensive training. Communication problems often complicate medical management on board. Effective communication and knowledge of patient's medical history and risk profile is very important to reviewing physician. Effective diagnosis depends on accurate and objective description of symptoms and clinical condition.
\end{abstract}

(Int Marit Health 2017; 68, 4: 190-195)

Key words: merchant ships, tele-medical assistance, cardiac cases, cardiovascular disease

\section{INTRODUCTION}

Cardiovascular diseases (CVD) have traditionally been a major concern in commercial maritime operations, mainly due to the potential risk of serious complications such as sudden death. Although cardiovascular cases are not a frequent cause of telemedical advice $\left(11^{\text {th }}\right.$ cause telemedical advice [1]) they remain the principal cause of medical emergencies, medical evacuations and natural deaths on board [2, 3]. It might be assumed that seafarers constitute a healthier population compared to employees ashore (healthy worker effect) since their medical fitness is certified at least biennially. However, risks for CVD seem to be similar or even elevated in relation to the reference population ashore (working on board increases risk?) [4-6]. Seafarers seem

Charalampos Apostolatos, Med Solutions International, 57 West 57 St., 10019, NYC, United States, e-mail: bbhbabis@gmail.com 
to be a group of workers with evidence of poor health [7]. Lifestyle factors like smoking, high-fat and unbalanced diet on board, obesity and heavy alcohol consumption [8, 9], work-related factors like elevated levels of stress due to long working hours and time pressure [10] along with lack of direct access to proper medical care [9] contribute to increased CVD risk on board. The prognosis of an acute myocardial infarction on board is poor [11]. Effective cardiopulmonary resuscitation is often delayed and outcomes are poor [6]. Studies have shown that recording and transmitting electrocardiogram (ECG) is technically feasible and enables timely initiation of antithrombotic therapy [12]. More intensive training of deck officers remains a fundamental measure against potential cardiovascular emergencies [3], while the applicability of automated external defibrillators remains controversial [1]. The prompt implementation of the pre-employment medical examinations (PEMEs) is the cornerstone of CVD prevention.

The objective of this study is to investigate the morbidity of CVD and events reported within a year to Med Solutions International telemedical assistance company and to analyse management and outcome of cases so as to provide valuable information in order to improve telemedical assistance services in future.

\section{MATERIALS AND METHODS}

The study used data from all cases reported within a year (2016) to Med Solutions International from 5 major shipping companies requiring telemedical assistance on board for a total of 212 ships, mainly container ships and tankers, travelling in deep waters, international routes, with average 25 crewmembers each (totally more than 5000 officers and ratings). Four out of 5 shipping companies employ mainly Greek officers and Filipino ratings while the $5^{\text {th }}$ company has mainly Indian and Chinese officers and ratings.

Cardiovascular cases were considered those cases reporting symptoms from chest, mainly chest pain, shortness of breath, palpitations, dizziness, loss of consciousness or peripheral blood vessels, high blood pressure or indications of a thromboembolic episode.

Next to an incident on board, minor or urgent, the master would contact with Med Solutions either through telecommunication or email with details about the incident, vital signs, symptoms and general condition as well as the position of the vessel. Med Solutions' medical team would provide accordingly instructions for the management on board and monitor his condition during the following days as well as arrange medical examination ashore if needed or medical evacuation. None of the vessels had a doctor on board and there were no ECG recorders available. Telecommunication data, emails, medical reports from hospitals where examinations were done and cases' final medical re-

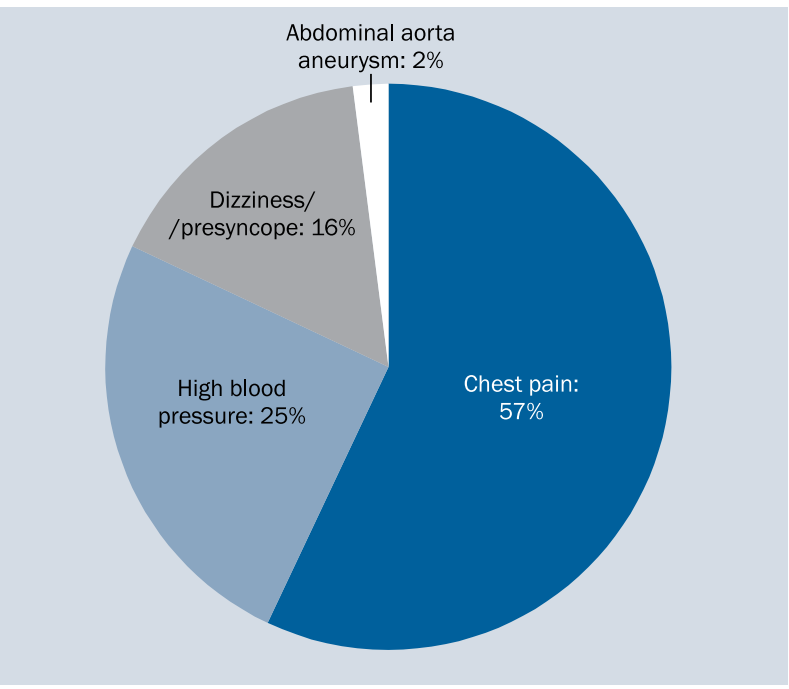

Figure 1. Cases with cardiovascular symptoms

ports to the shipping companies were analysed. Initial data reported often lacked basic information such as medical history and cardiovascular risk factors as this was either not known to officer reporting case and/or seafarer did not disclose said information.

\section{RESULTS}

Among 551 total cases reported within 2016 to Med Solutions, cases involving cardiovascular symptoms were 44 (8\%) (Fig. 1). All seafarers were men. Percentages fluctuated widely between $4.2 \%$ and $20 \%$ in different companies. The non-Greek company had a low percentage of $6.1 \%$.

Chest pain was reported in 25 cases out of 44 (57\% of initially suspected cardiovascular cases, $4.5 \%$ of total cases). Among those patients there were 10 officers and 15 ratings. Total mean age: 36.3 (officers: 35.1 , ratings: 37.1$)$.

Among the patients with chest pain only 1 was a confirmed heart attack (acute myocardial infarction). This was a 42-year-old Greek AB seafarer without history of heart disease but a heavy smoker. The seafarer was on board a ship which was off the coast of Venezuela. Initially reported symptoms - strong chest pain radiating to the back and shortness of breath - caused physician to immediately suspect myocardial infarction. There was no ECG recorder on board. The patient was given oxygen, low molecular weight heparin, nitrates and furosemide and he was urgently evacuated by a launch boat to the coast and transferred to medical facility for further treatment, reaching hospital several hours after pain started. He was diagnosed with an acute anterior myocardial infarction and coronary angiography was performed the following days, after testing for myocardial viability. 
Table 1. Chest pain cases

\begin{tabular}{lll}
\hline Chest pain cases & $\begin{array}{l}\text { Initial } \\
\text { diagnosis }\end{array}$ & $\begin{array}{l}\text { Confirmed } \\
\text { diagnosis }\end{array}$ \\
\hline True cardiovascular cases & 2 & 2 \\
Musculoskeletal symptoms & 13 & 11 \\
Respiratory infection & 4 & 6 \\
Undefined - stress & 5 & 5 \\
Gastroenteritis + chest pain & 1 & 1 \\
Total & 25 & 25
\end{tabular}

Among the rest of the patients with chest pain there was a patient with history of myocarditis and recurrent chest pain. He was on treatment with beta-blockers and he was examined ashore the same day with no ECG findings (but no troponin I was tested). He was sent back to ship but due to recurrent pain, he disembarked and was repatriated for further observation.

Also, there were 13 patients reporting pain with musculoskeletal characteristics (not implying possible cardiovascular condition). There were 4 patients with symptoms of respiratory infection (pleuritic pain, fever, cough) and 1 patient with combined chest and abdominal symptoms and final diagnosis of gastroenteritis who also recuperated on board. Onboard diagnosis seemed to coincide in most cases of typical musculoskeletal pain or respiratory infection. From the 11 (out of 13) cases with musculoskeletal type pain examined ashore, only 2 revealed underlying respiratory infection while the 2 cases with symptoms of infection which were examined ashore confirmed onboard diagnosis (Table 1).

However, there were also 5 patients with undefined symptoms including chest pain, shortness of breath, dizziness, loss of consciousness suggesting possible panic attack, stress or overexertion. They were all sent for medical examination ashore with inconclusive diagnosis: abdominal pain/gastro-oesophageal reflux - hiatus hernia/gastritis/ sinusitis etc.

In most of cases, chest pain was reported within $48 \mathrm{~h}$ from the time it started. From the total of 25 patients with chest pain, 20 were transferred for medical examination ashore and 5 were treated on board (including 2 cases of musculoskeletal pain, 2 cases of respiratory infection and the case with gastroenteritis) with clinical improvement confirming initial diagnosis and not requiring further medical evaluation. Transfer ashore was done in mean 2.1 days (median: 1 day - there were 2 cases which were transferred after 10 and 15 days). There were only 2 urgent medical evacuations. Only 4 cases required inpatient hospitalization. In total, 7 cases were declared unfit for duty.

High blood pressure was involved in 11 cases (25\% of cardiovascular cases, $2 \%$ of total) mean age: 50.2 years old
(4 officers - mean: 53.5 years old, 7 ratings - mean: 48.2 years old). From patients who reported high blood pressure there was one episode of acute pulmonary oedema. This was a 60-year-old Greek chief engineer who had a history of heart failure, arterial hypertension and diabetes mellitus. He was given diuretics on board and was evacuated urgently the same day to hospital where he was diagnosed with acute coronary syndrome and decompensated heart failure. He was kept in hospital and later repatriated.

Six out of 11 patients had a history of arterial hypertension (in one case the seafarer had run out of medication). Eight out of 11 patients were eventually, examined ashore while blood pressure of the other 3 was regulated with medical treatment on board. Three patients were admitted in hospital. Six out of 11 patients were eventually unfit for duty and repatriated.

Dizziness/loss of consciousness was reported in 7 cases (16\% of cardiovascular cases, $1.2 \%$ of total), mean age: 33 years old ( 2 officers, 5 ratings). One 35-year-old officer reported blurry vision and dizziness and was examined ashore with a diagnosis of possible transit ischaemic attack requiring magnetic resonance imaging and another 24-year-old officer had an episode of vasovagal syncope. There were 4 episodes which may be attributed to heat stroke (patients reported cramps, dizziness and shortness of breath). One of those 4 was found unconscious and was transferred urgently through the coast guard to hospital where dehydration and renal failure were diagnosed. Another patient had symptoms of panic attack. Three patients out of total were eventually unfit for duty and repatriated.

Abdominal pain was reported by a patient with history of aneurysm of the abdominal aorta. He was examined ashore and found to be stable - fit for duty.

In summary, during 2016, among 551 cases reported to Med Solutions, there was only one heart attack and one case of acute pulmonary oedema complicating an acute coronary syndrome. There was also a case of suspected myocarditis. From a total of 44 cases initially reporting cardiovascular symptoms, 11 cases had final diagnosis of typical musculoskeletal chest pain and 6 had respiratory infection. Ten patients reported symptoms related to high blood pressure (11 patients including the patient with acute pulmonary oedema). Episodes of dizziness or loss of consciousness were attributed to heat stroke or panic attack. There were patients with undefined symptoms mostly attributed to stress, overexertion or panic (Table 2).

No deviations of ships were necessary in the time period studied among the population of seafarers covered. There were only 4 (9\%) urgent medical evacuations done either by helicopter or launch boat/coast guard. Fortunately, the ship was close to the coast in 3 out of 4 cases and evacuation was done immediately. The fourth evacuation was done 
Table 2. Final results: cases with cardiovascular (CV) symptoms

\begin{tabular}{llll}
\hline Final results: CV cases & No. & CV cases (\%) & Total cases (\%) \\
\hline Acute myocardial infarction & 1 & $2 \%$ & $0.2 \%$ \\
Acute pulmonary oedema & 1 & $2 \%$ & $0.2 \%$ \\
Myocarditis (?) & 1 & $2 \%$ & $0.2 \%$ \\
High blood pressure & 10 & $23 \%$ & $1.8 \%$ \\
Musculoskeletal chest pain & 11 & $25 \%$ & $2 \%$ \\
Respiratory infection & 6 & $14 \%$ & $1 \%$ \\
Gastroenteritis & 1 & $2 \%$ & $0.2 \%$ \\
Transient ischaemic attack (?) & 1 & $2 \%$ & $0.2 \%$ \\
Vasovagal syncope & 1 & $2 \%$ & $0.2 \%$ \\
Heat stroke & 4 & $10 \%$ & $0.8 \%$ \\
Aneurysm abdominal aorta stable & 1 & $2 \%$ & $0.2 \%$ \\
Stress - panic & 6 & $14 \%$ & $1 \%$ \\
Total & 44 & $100 \%$ & $8 \%$
\end{tabular}

the following day by helicopter. 32 out of 44 cases (72\%) were referred to further evaluation and exam ashore. Nine out of 44 cases (20\%) were admitted to hospital for further treatment. 16 (36\%) cases were, finally, unfit for duty and were repatriated.

\section{DISCUSSION}

All cases involved men and were evenly distributed among officers and ratings. Seafarers of different shipping companies seemed to ask for telemedical assistance for more or less serious symptoms, depending also on the ship's master. This explains different percentages of cases with cardiovascular symptoms in different companies. Seafarers of the 4 Greek shipping companies seemed to ask for telemedical advice more easily, often for insignificant symptoms; therefore, percentages of cases with cardiovascular symptoms were higher than the company employing Chinese and Indian seafarers.

The most significant finding from this study is that the number of confirmed cardiovascular cases was very low. There was only 1 heart attack and 1 pulmonary oedema complicating acute coronary syndrome. There was also 1 case of suspected myocarditis. In most cases chest pain had musculoskeletal origin or was due to respiratory infection. Those cases were either referred ashore for examination or treated on board (non-steroid anti-inflammatory agents or antibiotics) with clinical improvement confirming initial diagnosis. Another significant finding from this study is the importance of psychological factors in symptoms and clinical condition of the seafarers. A large number of patients describe various symptoms from different parts of the body which cannot be combined with each other, e.g. atypical chest pain. We often suspect symptoms are result of stress or even panic attack and recommend monitoring symptoms and symptomatic therapy. Even simple musculoskeletal symptoms are often amplified due to the patient's anxiety and blood pressure remains elevated when it is measured several times per day. Unfortunately, seafarers occasionally present dramatic symptoms, the severity of which cannot be ignored. All such cases were sent ashore for thorough examination but diagnosis was usually inconclusive. Characteristic is the case of a 28-year-old Indian seafarer urgently evacuated by helicopter upon arrival to Cape Horn because he reported a dramatic clinical condition with severe chest pain and shortness of breath despite treatment on board with oxygen, nitrates and aspirin. There was no ECG recorder on board. As soon as he disembarked, he reported immediate improvement of symptoms. The initial symptoms may have simply been product of fear? Panic? It is understandable to feel insecurity in the middle of the ocean but it seems that stress and fear at least contribute to a significant number of reported cardiovascular cases.

Since the possible outcome of a cardiac incident or condition may be extremely serious with a high mortality rate, it is important to intensify prevention techniques as well as pursue adequate training procedures to improve management of such cases. The best prevention is the PEME procedure. However, this study showed that the efficiency of PEMEs is often questionable. Seafarers are assumed to be healthy and having passed tests to confirm their fitness for duty at sea. However, seafarers often do not disclose true medical problems and medications taken in fear of not being employed. Medical history and risk factors are not reported for the vast majority of patients limiting the 
efficiency of the PEME procedures. Occasionally, medications were discovered in the cabins for conditions for which the shipping company and the master of the ships are not aware. We discovered patients in this study with multiple risk factors, heart failure, recent myocarditis and often uncontrolled arterial hypertension, incompatible with duty especially on high seas. There was a patient with high blood pressure examined ashore whose echo revealed a flail mitral valve with severe mitral regurgitation (unknown if it existed during PEME). Blood pressure in many cases is completely uncontrolled and in other cases seafarers simply run out of medications during the duration of the voyage (inadequate quantity of medication is brought on board in relation to duration of the journey). Although tele-medical assistance provided instructions for diet, daily measurements and treatment on board, there were not always sufficient anti-hypertensive drugs on board. Seafarers are supposed to have regulated risk factors before travel and received specific instructions during PEME procedures regarding diet, medications and healthy lifestyle. Previous conditions like heart failure, myocarditis, severe mitral regurgitation should be managed accordingly and certificates of restricted or limited fitness for duty should be issued.

Another common important issue is often the lack of effective communication. Despite the availability of means, telephone and internet, the language barrier between officers and ratings and cultural differences often make communication difficult. In some cases, a patient is referred for exam ashore and he comes back with a completely different diagnosis than the initially reported symptoms would imply. Symptoms are either not clearly reported, information is left out or, in many instances, seafarer reporting condition does not do so objectively. Frequently, he has reached a conclusion/diagnosis on his own, therefore, reporting to the physician only those symptoms he considers significant.

Since true cardiac events occur, even rarely, there should be adequate training to learn to handle such cases, initially on board and later by transfer to medical facilities. A medical officer or the captain must know how to provide first aid and use the medical supplies on board in communication with the doctor from telemedical assistance. Medical equipment often includes an ECG recorder or even automatic defibrillators. In our case, diagnosis of the heart attack and the pulmonary oedema was clinically based on the clinical condition, symptoms and signs. Treatment was given accordingly on board until the patient was evacuated.

ECG is a valuable tool for the evaluation of the patient but it is not sufficient alone for correct diagnosis. Often severe cardiac events have no ECG findings and this may confuse the doctor providing telemedical assistance. ECG might dictate the use of thrombolysis if a typical ST-elevation myocardial infarction is recorded on the ECG but thromboly- sis is not advisable to be done by a non-doctor. In the case of suspected myocarditis, ECG might also be of no use since there are often no ECG findings and diagnosis depends on clinical symptoms and blood tests (heart biomarkers). In such cases rapid troponin tests might be helpful if appropriate training was provided. Automatic external defibrillators require minimum training but have not been widely used yet. Therefore, a detailed history with precise description of the patient's signs and symptoms remains the most important elements for diagnosis on board. The doctor relies exclusively on the patient to describe accurately his symptoms and the master of the ship to describe objectively his clinical condition and to follow the exact instructions given. Thus, training is the most important factor in management of such life-threatening cases on board, while clear and effective communication between physician and patient is critical in maritime.

\section{CONCLUSIONS}

1. The number of confirmed cardiovascular cases was very low.

2. Psychological factors and stress often amplify the severity of symptoms.

3. Prevention of CVD should be intensified through more efficient PEMEs.

4. Effective communication plays a significant role in reporting medical cases on board.

5. Communication training could help reduce the number of emergency cases on board.

6. Communication and knowledge of medical history and risk factors is very important to reviewing physician.

7. The doctor relies on the captain for an objective review of symptoms and vital signs as well as compliance with all medical instructions outlined.

\section{ACKNOWLEDGMENTS}

Many thanks to Vivian Andria and Julie Licari for their valuable contribution to this study and for providing me with all necessary data and helping in statistical analysis. Being a lead physician for Med Solutions International has been a very rewarding experience. Many thanks, also, to Professor Olaf Chresten Jensen for helping me finalise this project.

\section{REFERENCES}

1. Alves PM, Leigh R, Bartos G, et al. Cardiovascular events on board commercial maritime vessels: a two-year review. Int Marit Health. 2010; 62(3): 137-142, indexed in Pubmed: 21154300.

2. Grappasonni I, Petrelli F, Amenta F. Deaths on board ships assisted by the Centro Internazionale Radio Medico in the last 25 years. Travel Med Infect Dis. 2012; 10(4): 186-191, doi: 10.1016/j. tmaid.2012.06.006, indexed in Pubmed: 22819258.

3. Oldenburg M, Rieger J, Sevenich C, et al. Nautical officers at sea: emergency experience and need for medical training. J Occup Med Toxicol. 2014; 9: 19, doi: 10.1186/1745-6673-9-19, indexed in Pubmed: 24817903. 
4. Oldenburg $M$, Jensen $H J$, Latza $U$, et al. Oldenburg $M$, Jensen $H J$, Latza $U$, et al. The risk of coronary heart disease of seafarers on vessels sailing under a German flag. Int Marit Health. 2010; 62(3): 123-8, indexed in Pubmed: 21154298.

5. Oldenburg M, Jensen HJ, Latza U, etal. Coronary risks among seafarers aboard German-flagged ships. IntArch Occup Environ Health. 2008; 81(6): 735 741, doi: 10.1007/s00420-007-0261-5, indexed in Pubmed: 17909838.

6. Oldenburg M. Risk of cardiovascular diseases in seafarers. Int Marit Health. 2014; 65(2): 53-57, doi: 10.5603/IMH.2014.0012, indexed in Pubmed:25231325.

7. Hansen HL, Tüchsen F, Hannerz H. Hospitalisations among seafarers on merchant ships. Occup Environ Med. 2005; 62(3): 145-150, doi:10.1136/oem.2004.014779, indexed in Pubmed: 15723878.

8. Textbook of Maritime Medicine, Norwegian Centre for Maritime Medicine.
9. Roberts SE. Mortality from disease among seafarers in British merchant shipping (1976-1995). Int Marit Health. 2002; 53(1-4): 43-58, indexed in Pubmed: 12608588.

10. Oldenburg M, Baur X, Schlaich C. Cardiovascular diseases in modern maritime industry. Int Marit Health. 2010; 62(3): 101-106, indexed in Pubmed:21154295.

11. Jaremin B, Kotulak E. Myocardial infarction (MI) at the work-site among Polish seafarers. The risk and the impact of occupational factors. Int Marit Health. 2003; 54(1-4): 26-39, indexed in Pubmed: 14974775.

12. Vallé B, Camelot D, Bounes V, et al. Cardiovascular diseases and electrocardiogram teletransmission aboard ships: the French TMAS experience. Int Marit Health. 2010; 62(3): 129-136, indexed in Pubmed: 21154299. 